\title{
AN OPHTHALMIC RULE
}

\author{
BV \\ N. BISHOP HARMAN \\ LONDON
}

THE ocular base line must be measured for every eye patient. The ophthalmic surgeon needs to measure it before proceeding tocertain detailed subjective investigations, e.g., binocular balance by means of the diaphragm test. The dispensing optician must measure it to determine the fit of spectacle frames and the centering of lenses.

In $1910 \mathrm{I}$ showed to the Ophthalmological Society a form of calipers or rule whereby this measurement could be made with accuracy and speed. This rule has been much used. A new pattern has now been made by Messrs. Theodore Hamblin which is a material improvement. In the first pattern the moving member or cursor slid on the rule so that a little dirt checked its free movement, and the wires by which the sighting is made were long

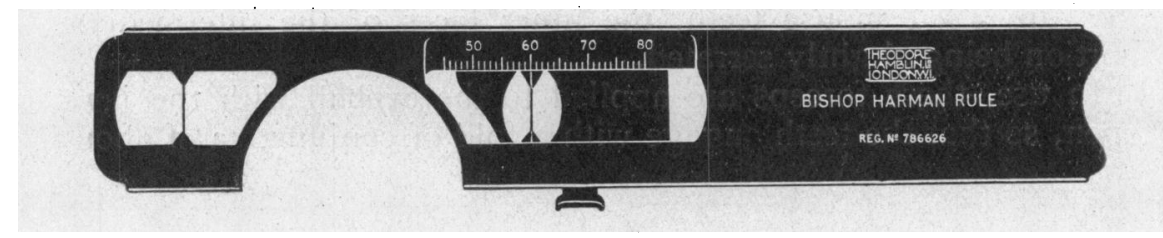

and easily bent. In the new model the position of the cursor has been reversed, it now slides within the channelled frame of the rule. These channels give wide bearings with free yet steady movement to the cursor, and the interior housing gives protection to the wires. The new rule is made of duralmin stampings, so that each rule is mathematically exact. It weighs only half an ounce, yet it is so strong that it may be carried in the pocket. The wires are of fine steel, wedged into the cursor by taper pins. The rule is black, with the millimeter scale engraved and filled in with white. There is a full range of 45 to $80 \mathrm{~mm}$. The scale has a sharply bevelled edge so as to obviate parallax between the scale and the wire.

In use, the rule should be held in the right hand with the root of the little finger crooked into the notch on the end of the handle, the thumb falls naturally into place on the little thumb piece at the lower edge of the rule which is part of the cursor. The patient looks at a light in the distance and the observer sights with his own left eye the wire of the rule against the spot of light on the patient's right eye, and with his own right eye sights the other wire over the spot of light on the patient's left eye. For 
near vision the patient fixes a near point and the distance between the corneal images of the light are taken as before.

The rule is obtainable from the manufacturers-Messrs. Theodore Hamblin, Ltd., Dispensing Opticians, 15, Wigmore Street, London, W.1.

\title{
A NEW CONJUNCTIVAL-FOLD FIXATION FORCEPS
}

\author{
BY \\ D. Stenhouse Stewart
}

HULL

Messrs. Down Brothers have made for me a pair of conjunctival-fold fixation forceps, each limb consisting of a curved foot fixed at an angle to the shank, the curvature of the foot being comparable to that of the sclera. At the heel and toe of this curved foot are $2 \times 1$ mouse teeth, the inner faces of the intermediate portion being slightly serrated.

In use, these forceps are applied to the eyeball with the jaws open, so that the teeth engage with a fold of conjunctiva of about

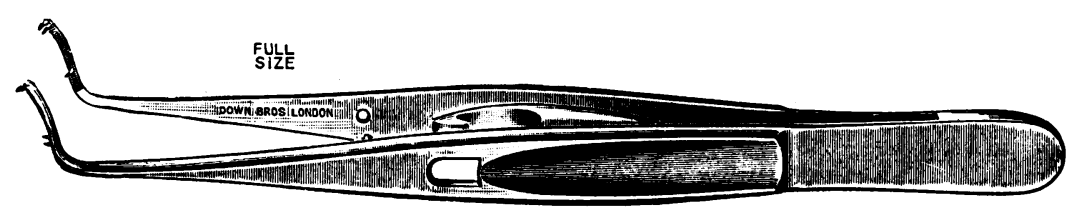

$8 \mathrm{mms}$. which rises between the jaws and is held there when the forceps closes. For convenience in handing to an assistant a spring catch is fitted.

The principal operation for which I use the forceps is that of iridencleisis, when a fold is taken as described, by fixing one limb at the upper corneal margin and drawing down the fold from conjunctiva which will ultimately cover the prolapsed iris. I introduce a Harrison Butler's knife through the conjunctiva, pass it beneath the forceps, the blades of which are as narrow as they can be, compatible with reasonable strength and rigidity, and enter it direct into the anterior chamber. The iris is drawn out, preferably with bottom toothed iris forceps with a curved foot of a similar type, after tearing its root by traction towards the pupil.

The drawn out portion can usually be released, and divided by de Wecker's scissors without transferring the fixation forceps to 